\title{
Quasi-horizontal circulation cells in 3D seawater intrusion
}

\author{
Elena Abarca $^{\text {a,* }}$, Jesús Carrera ${ }^{\text {a }}$, Xavier Sánchez-Vila ${ }^{\text {a }}$, Clifford I. Voss ${ }^{\text {b }}$
}

\author{
a Department of Geotechnical Engineering and Geoscience, Technical University of Catalonia, Barcelona, Spain \\ b US Geological Survey, 431 National Center, Reston, VA 20192, USA
}

Received 13 September 2006; received in revised form 31 January 2007; accepted 5 February 2007

\section{KEYWORDS \\ Seawater intrusion; Aquifer geometry; Bottom morphology; Lateral seawater circulation cell; Horizontal cell; Lateral buoyancy number; Seawater discharge}

\begin{abstract}
Summary The seawater intrusion process is characterized by the difference in freshwater and seawater density that causes freshwater to float on seawater. Many confined aquifers have a large horizontal extension with respect to thickness. In these cases, while buoyancy acts in the vertical direction, flow is confined between the upper and bottom boundaries and the effect of gravity is controlled by variations of aquifer elevation. Therefore, the effective gravity is controlled by the slope and the shape of the aquifer boundaries. Variability in the topography of the aquifer boundaries is one case where 3D analysis is necessary. In this work, density-dependent flow processes caused by 3D aquifer geometry are studied numerically and specifically, considering a lateral slope of the aquifer boundaries. Sub-horizontal circulation cells are formed in the saltwater entering the aquifer. The penetration of the saltwater can be quantified by a dimensionless buoyancy number that measures the lateral slope of the aquifer relative to freshwater flux. The penetration of the seawater intrusion wedge is controlled more by this slope than by the aquifer thickness and dispersivity. Thus, the slope must be taken into account in order to accurately evaluate seawater intrusion.

(C) 2007 Elsevier B.V. All rights reserved.
\end{abstract}

\section{Introduction}

Intrusion of seawater into coastal aquifers is a widespread contamination phenomenon that increasingly causes groundwater salinization problems worldwide. Seawater intrusion is especially severe in semiarid regions where

\footnotetext{
* Corresponding author. Tel.: +34 9340118 20; fax: +34 9340172 51.

E-mail address: elena.abarca@upc.edu (E. Abarca).
}

high-pumping extraction rates are coupled with low freshwater recharge. What makes seawater intrusion different and more complex than other solute transport problems is that the variation of concentration causes water density to vary in space and time. Density differences cause freshwater to float over seawater. This effect was first addressed by Ghyben (1889) and Herzberg (1901), who empirically found that the depth to saltwater correlates with freshwater head. Assuming steady-state freshwater flow and a sharp interface between fresh and saltwater, the depth of the 
freshwater/saltwater interface, $\boldsymbol{z}$, is $\epsilon \boldsymbol{z}=h$; where $h$ is the freshwater head, $\epsilon=\left(\rho_{\mathrm{s}}-\rho_{\mathrm{f}}\right) / \rho_{\mathrm{f}}$ where $\rho_{\mathrm{s}}$ and $\rho_{\mathrm{f}}$ are the seawater and freshwater densities, respectively. This is called the Ghyben-Herzberg approximation for seawater intrusion. Since $\epsilon$ is approximately equal to $1 / 40$, a common rule-of-thumb is to assume that the depth to seawater below sea level is 40 times the freshwater head above sea level.

A second effect associated with concentration differences is the mixing between the two fluids. Mixing is caused by diffusion/dispersion processes and results in some of the salt being driven seawards by freshwater. Replenishment of this salt requires an inland flow of seawater. The result is a vertical convection cell formed by seawater that flows landwards at depth and disperses into the freshwater flowing zone, where salt is flushed out by the discharging freshwater flow (Fig. 1). The equilibrium assumption of Ghyben-Herzberg is not valid because seawater flux causes an energy (head) loss. Therefore, the depth of the seawater wedge is underestimated. The above discussion indicates that seawater movement in coastal aquifers is caused by the combination of density driven flow and hydrodynamic dispersion. This effect was first discussed by Cooper (1964). When taking into account density effects, the groundwater flow and solute transport are coupled by the presence of the density in the gravity (buoyancy) term in the momentum balance equation of fluid.

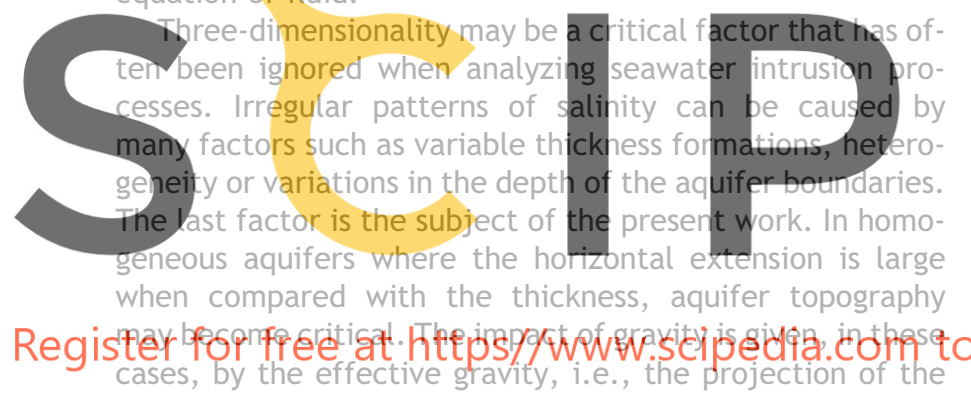

gravity vector on the boundary planes. The effective gravity is controlled by the slope and shape of the boundaries. When the lateral slope is large, vertical flow can diminish with respect to the lateral flow.

A number of geophysical studies provide evidence that seawater penetrates farthest inland in the deepest parts of coastal aquifers. Flores-Márquez et al. (1998) and more recently Rangel-Medina et al. (2003) compared the 3D shape of the basement of the Costa de Hermosillo aquifer (Mexico) with geochemical and geophysical data. The crystalline basement presents a structure of alternating horsts and grabens and the integration of all available data indicates that

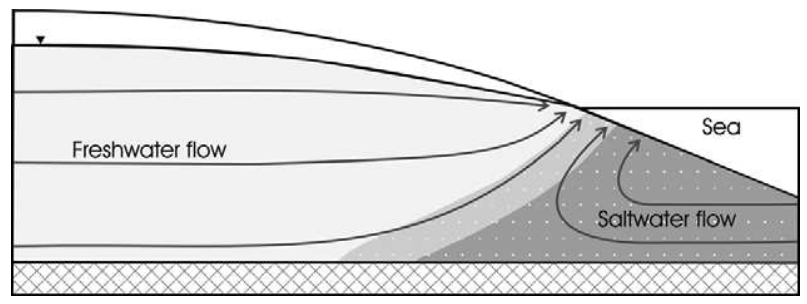

Figure 1 Classic vertical seawater circulation cell induced by the combination of buoyancy forces and hydrodynamic dispersion processes. preferential pathways for seawater intrusion correspond to the lineation of basement depressions (grabens). Yet, only 2D density dependent flow cross-sections of the aquifer were modelled. Thus, the three dimensionality of the flux due to the irregularity of aquifer bottom was not considered. Using the Direct Current method, Benkabbour et al. (2004) determined the depth of the bottom of the coastal aquifer of the Mamora Plain, Morocco and the lateral and vertical distribution of salinity. Seawater penetrates farthest inland in the proximity of the Sebou River, where the substratum is deeper. This deepest penetration was attributed to a greater aquifer thickness since seawater penetration inferred from Ghyben-Herzberg approximation is proportional to the square of the aquifer thickness. However, according to this assumption the total freshwater flow in each vertical section is constant. Buoyancy effects due to density differences were not taken into account.

The hydrogeological literature contains no qualitative analysis of the effect of aquifer morphology on seawater intrusion, although the need of such an analysis has been highlighted in a number of heat transport studies. In these studies, variable density was taken into account and the effect of aquifer slope in the heat plume movement and velocity was addressed. Bachu (1995) and Bachu and Karsten (2002) studied density driven flow in sloping aquifers, applying the results to two sedimentary basins: Alberta (Canada) and Los Llanos (Colombia). Malkovsky et al. (2002) high-

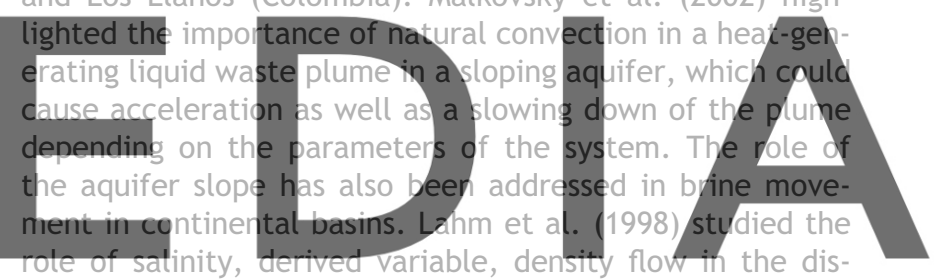

placement of brine from a shallow, regionally extensive

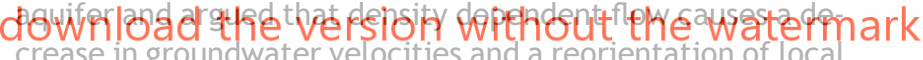
flow directions of the aquifer within the mixing zone, but their model was 2D. Assouline and Shavit (2004) studied the effects of management policies, including artificial recharge, on salinization in a sloping aquifer in Israel. Although seawater intrusion processes were not taken into account, the importance of the thickness variations in the sloping aquifer in the salinization process was addressed.

3D modeling of density-dependent flow and solute transport is a useful tool to assess the effect of aquifer morphology in seawater intrusion. Until recently, 3D models had not been practical owing to excessive demands of computer time. As a result, most seawater modeling studies consisted of 2D cross-section models or sharp interface models. However, 3D density-dependent flow models have been developed in the last decade, giving rise to better ways to model advective and dispersive mechanisms with fluid density and viscosity effects. Nowadays, many codes are available: FEFLOW (Diersch and Kolditz, 1998), ROCKFLOW (Kolditz et al., 1998), HST3D (Kipp, 1986), TVDT3D (Ackerer et al., 1999), METROPOL (Sauter et al., 1993), MVAEM (Strack, 1995), MOCDENSE3D (Oude Essink, 1998), SWICHA (Huyakorn et al., 1987), SWIFT (Ward, 1991), CODESA (Gambolati et al., 1999), SUTRA (Voss and Provost, 2002), SEAWAT (Guo and Langevin, 2002) and $d^{3} f$ (Fein and Schneider, 1999). A recent state-of-the-art of density-dependent 
flow modeling in porous media can be found in Diersch and Kolditz (2002). Improvements in computer speed have facilitated the construction of adequately refined grids to reduce problems of numerical dispersion, which accounts for the emergence of 3D benchmark problems (Johannsen et al., 2002; Oswald and Kinzelbach, 2004) for density dependent codes. Variable density 3D models of real cases are also becoming increasingly frequent (Oude Essink, 2001; Xue et al., 1995; Sciabica et al., 1994; Gambolati et al., 1999; Paniconi et al., 2001; Gingerich and Voss, 2002; Milnes and Renard, 2004). Complex geometries have been included in these models but with no reference to the effect of the shape of the boundaries in the analysis of the results.

In summary, emphasis has been never been placed on analyzing the effect of aquifer topography on seawater intrusion, especially the effect of lateral variations in aquifer depth. The aim of this paper is to test the hypothesis that the topography of the aquifer bottom could significantly affect seawater intrusion patterns in coastal aquifers. First, the governing equations and some dimensionless numbers that can be used to characterize the effects upon groundwater flow patterns of aquifer bottom topography are presented. Then, a set of numerical simulations including a sensitivity analysis is used to highlight the potential role of this phenomenon in coastal aquifers.

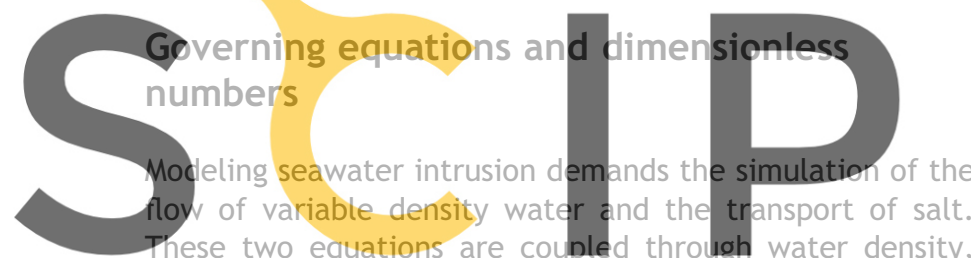
which enters the flow equation and is a function of concen-

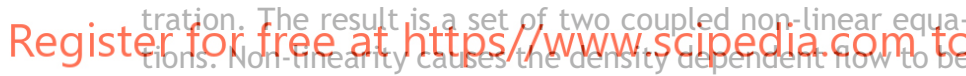
very sensitive to boundary conditions and to variability in the permeability field. Non-linearity causes fingering and rotational flow with closed streamlines when the initial configuration of the system is not stable. This calls for a thorough description of the $3 \mathrm{D}$ problem. Equations governing these phenomena are presented in this section.

\section{Flow equation}

Flow of any fluid is governed by mass and momentum conservation. Mass conservation can be written as

$\frac{\partial \rho \phi}{\partial t}=-\nabla(\rho \boldsymbol{q})+\rho^{*} \boldsymbol{Q}_{h}$,

where $\rho$ is the fluid density $\left(\mathrm{kg} / \mathrm{m}^{3}\right), \phi$ is porosity (volume of voids per unit volume of aquifer), $\boldsymbol{q}$ is fluid flux $\left(\mathrm{m}^{3} / \mathrm{s} \mathrm{m}^{-2}\right)$, and $Q_{h}$ is the sink/source term $\left(\mathrm{m}^{3} / \mathrm{s}\right.$ of fluid per unit volume of aquifer), $\rho^{*}$ is the density of the incoming water when $Q_{h}>0$ and the density of the resident outflowing groundwater when $Q_{h}<0$.

Dependence of density on solute mass fraction is frequently described by a linear or an exponential law Kolditz et al., 1998. A linear equation would read

$\rho(\omega)=\rho_{\mathrm{f}}+\beta_{\omega}\left(\omega-\omega_{\mathrm{f}}\right)$, where $\omega$ is the solute mass fraction ( $\mathrm{kg}$ of salt $/ \mathrm{kg}$ of fluid), $\beta_{\omega}$ is the constant relation between the density and the salt mass fraction variation, $\omega_{\mathrm{f}}$ is the freshwater salt mass fraction and $\rho_{\mathrm{f}}$ is the density of freshwater. Viscosity variations with seawater concentration are considered negligible and are not considered in this work.

The flow equation can be written in terms of either pressure $p(\mathrm{~Pa})$ or equivalent freshwater head $h_{\mathrm{f}}(\mathrm{m})$. The freshwater equivalent head is defined as

$h_{\mathrm{f}}=\frac{p}{\rho_{\mathrm{f}} g}+z$.

Momentum conservation in flow through porous media is expressed by Darcy's law

$\boldsymbol{q}=-\frac{\boldsymbol{k} \rho_{\mathrm{f}} \mathrm{g}}{\mu}\left[\nabla \boldsymbol{h}_{\mathrm{f}}+\alpha \nabla \mathbf{z}\right]$,

where $k$ is the intrinsic permeability tensor $\left(\mathrm{m}^{2}\right), \mu$ is the fluid viscosity $(\mathrm{kg} / \mathrm{m} \mathrm{s}), \alpha=\left(\rho-\rho_{\mathrm{f}}\right) / \rho_{\mathrm{f}}$ and $\nabla \mathrm{z}$, in $3 \mathrm{D}$, represents a unit vector opposite to gravity. It is common to write (4) in terms of the hydraulic conductivity of freshwater $K=K \rho_{\mathrm{f}} \mathrm{g} / \mu$. The second term in Eq. (4), $K \alpha \nabla z$, represents buoyancy.

Finally, expanding (1) and using (4), the mass balance equation for general saturated problems is

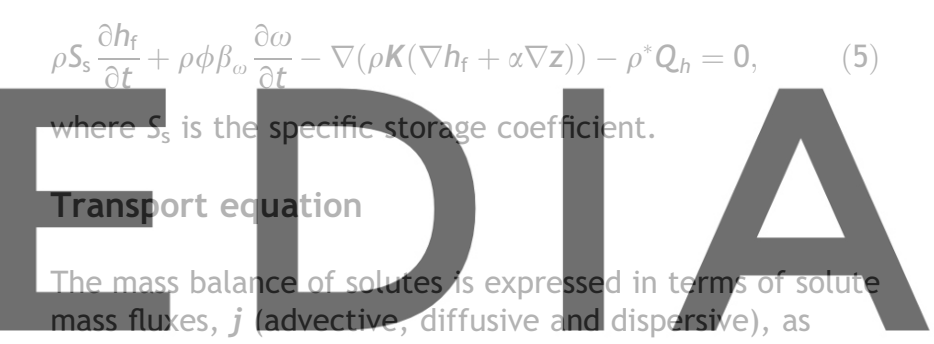

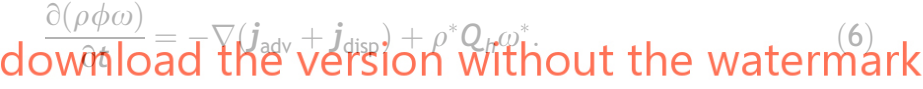

The advective mass flux is equal to $j_{\text {adv }}=\rho q \omega$. The dispersive and diffusive fluxes are treated together as $j_{\text {disp }}=$ $-\rho D \nabla \omega$ where $\boldsymbol{D}$ is the hydrodynamic dispersion tensor.

\section{Dimensionless numbers}

This analysis applies to horizontally extensive aquifers, where thickness is relatively small. Under these conditions, flow can be assumed to be constrained by the aquifer top and bottom boundaries and can be expressed in $2 \mathrm{D}$ as

$b \boldsymbol{q}=\boldsymbol{T}\left(\nabla h_{\mathrm{f}}+\alpha \boldsymbol{m}\right)$.

Here, $b$ is the aquifer thickness, $q=\left(q_{x}, q_{y}, 0\right), T$ is transmissivity (typically $T_{x x}=b K_{x x}, T_{x y}=b K_{x y}$ and so forth) $\boldsymbol{m}=\left(m_{x}, m_{y}, 0\right)$ is the aquifer slope. Notice that Eq. (7) implies that the vertical buoyancy term of Eq. (4) is projected onto the aquifer surface.

The relative importance of buoyancy and freshwater pressure can be expressed by comparing the two terms in Eq. (7). The first one, $T \nabla h_{\mathrm{f}}$, can be approximated by a characteristic water flow, $b \boldsymbol{q}_{\mathrm{c}}$, where $\boldsymbol{q}_{\mathrm{c}}$ is a characteristic flux. In coastal aquifers, at large scales, this term is directed seawards. The direction of the second term, $T \alpha \mathrm{m}$, is controlled by the aquifer slope. Adopting $\alpha=\epsilon$, i.e., using seawater as reference characteristic density, the following dimension- 
less number can be defined to express the ratio between the buoyancy and pressure forces:

$N_{\mathrm{b}}=\frac{\epsilon|\boldsymbol{T} \boldsymbol{m}|}{b\left|\boldsymbol{q}_{\mathrm{c}}\right|}=\frac{\epsilon|\boldsymbol{m}|}{\left|\nabla \boldsymbol{h}_{\mathrm{f}}\right|}$.

In a horizontally large aquifer with a slope of $4 \%$, the buoyancy becomes $0.1 \%$ and is comparable to typical values of the hydraulic gradient. This comparison suggests that buoyancy forces may play a critical role in this type of aquifer.

However, for the purposes of this work it is more appropriate to consider a "lateral buoyancy" dimensionless number, $N_{\text {by }}$, by comparing the seawards driving force with the lateral component of buoyancy ( $y$ coordinate, parallel to coast):

$N_{\text {by }}=\frac{\epsilon\left|\boldsymbol{T} m_{\mathrm{y}}\right|}{b\left|\boldsymbol{q}_{\mathrm{c}}\right|}=\frac{\epsilon m_{\mathrm{y}}}{\left|\nabla h_{\mathrm{f}}\right|}$,

where $m_{y}$ is the maximum lateral slope (parallel to the coast) of the aquifer bottom.

The dimensionless number defined in (8) resembles the driving forces ratio (DFR) proposed by Bachu (1995) and Bear, 1972 to define free and forced convection in vertical flow.

DFR

$$
=\frac{\epsilon}{\nabla h_{\mathrm{f}}} \text {. }
$$

We prefer to express the $N_{\mathrm{b}}$ and $N_{\mathrm{by}}$ numbers in terms of freshwater flux because a characteristic flux can be more

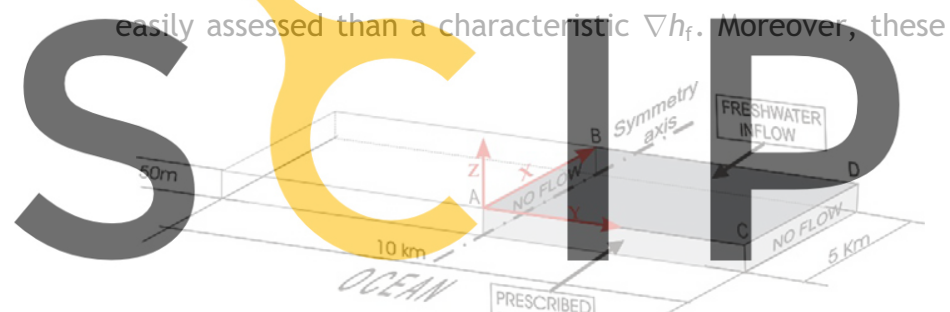

Register for free at https//www.scipedia.com to Figure 2 Geometry of the aquifer and model domain (grey area), including boundary conditions: freshwater inflow from iniand and prescribed pressure in the seaside boundary.

CASE 1: Horizontal aquifer

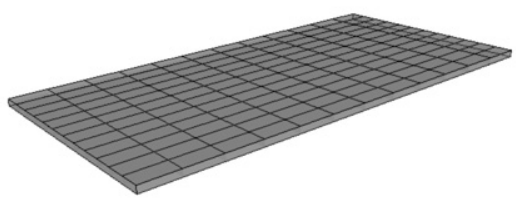

CASE 3: V-shaped aquifer

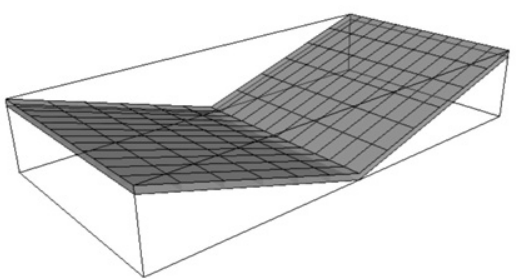

numbers explicitly take into account the aquifer slope, which conditions the buoyancy forces in geometrically confined aquifers. This has been recognized by Dorgarten and Tsang (1991) who proposed an expression for DFR essentially identical to (8), although motivated by heat transport. Yet, $N_{\text {by }}$ is preferred because it is the lateral slope $\left(m_{y}\right)$ that causes flow to depart from the vertical plane.

\section{Numerical modeling methodology}

A numerical methodology is employed to evaluate the extent to which aquifer depth variation can contribute to irregularities in seawater intrusion patterns. A 3D model of a confined aquifer of constant thickness is considered. An aquifer size of $10,000 \times 5000 \mathrm{~m}^{2}$ and $50 \mathrm{~m}$ of thickness is chosen resembling typical dimensions of coastal aquifers. In order to save computation time, the numerical analysis was carried out modeling only half of the symmetric aquifer (see Fig. 2).

A number of aquifer geometries of a horizontally large confined aquifer of constant thickness, such as the one presented in Fig. 3, were studied. They can be divided into four groups: (1) "horizontal", (2) "sloping" (towards the sea), (3) "V-shaped" (with a central deeper section) and (4) a "warped" aquifer (curved with a deeperx point located in the middle of the seaside boundary). All geometries were

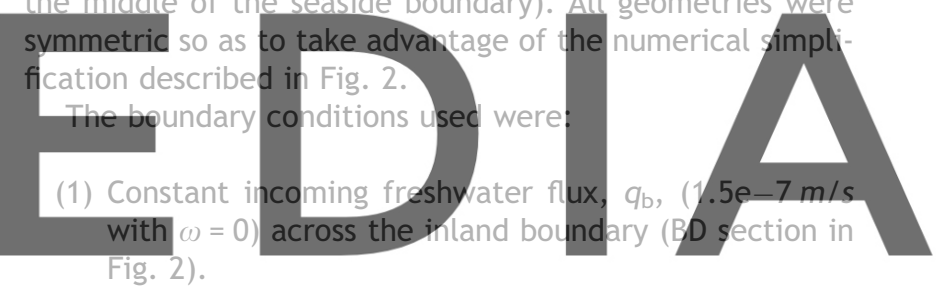

(2) Prescribed pressure $\left(p=\rho_{s} g z\right)$ along the seaside

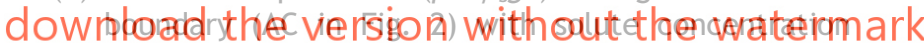
equal to seawater concentration for inflowing portions and resident concentration for outflowing boundaries, as expressed by the equation:

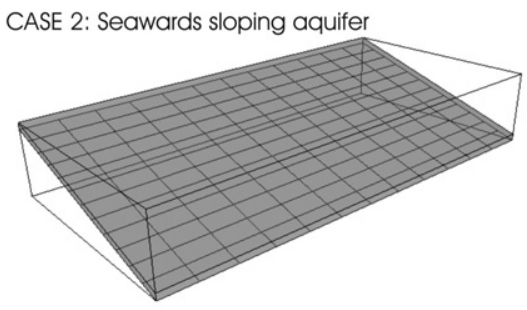

CASE 4: Warped aquifer

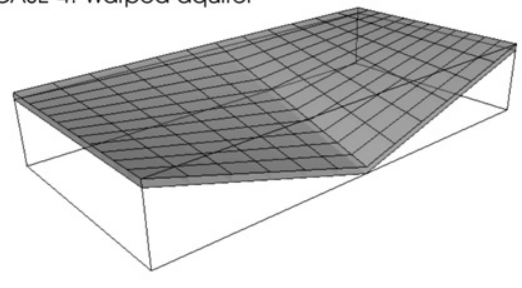

Figure 3 Schematic description of the test cases geometries: (1) horizontal, (2) seawards sloping, (3) V-shaped and (4) warped. Freshwater flows from the background (inland) towards the foreground (seaside). $Y$ coordinate is parallel to the coast or long dimension of schematics. 
$\left(\boldsymbol{j}_{\mathrm{adv}}+\boldsymbol{j}_{\mathrm{disp}}\right) \cdot \boldsymbol{n}=\left\{\begin{array}{ll}\boldsymbol{q} \rho \omega & \text { if } \boldsymbol{q}>0 \\ \boldsymbol{q} \rho_{\mathrm{s}} \omega_{\mathrm{s}} & \text { if } \boldsymbol{q}<0\end{array}\right.$,

where $\mathrm{n}$ is the is normal to the boundary pointing outwards. Fluid enters the aquifer with seawater concentration, but exits with aquifer's concentration.

(3) The remaining boundaries (vertical planes passing through $A B$ and $C D$ in Fig. 2 and top and bottom surfaces) were closed to flow and solute transport.

Both sea level and the horizontal plane (ABCD in Fig. 2) were set at $z=0$. Flow and transport parameters used for the simulation are specified in Table 1 . The dispersivity coefficients were chosen to accomplish stability criteria. The anisotropic dispersivity tensor of SUTRA has three different values of the longitudinal dispersion coefficient $\left(\alpha_{\mathrm{L}}\right)$ to allow dispersion to vary depending on flow direction (Voss and Provost, 2002). Given the difference between the horizontal and vertical scale of the domain, $\alpha_{L_{z}}$ was chosen ten times smaller than $\alpha_{L}$ for horizontal flow directions $\left(\alpha_{L_{x}}\right.$ and $\left.\alpha_{L_{*}}\right)$. For the sake of simplification, the transverse dispersivity coefficient $\left(\alpha_{T}\right)$ is the same for all flow directions and equal to $\alpha_{L_{r}} / 10$.

The simulated cases are depicted in Table 2 in accor dance with the shape of the boundary planes; $m_{x}$, the seawards slope at the central section (AB in Fig. 2 ) and $m_{y}$, the lateral slope at the seaside boundary (AC in Fig. 2).

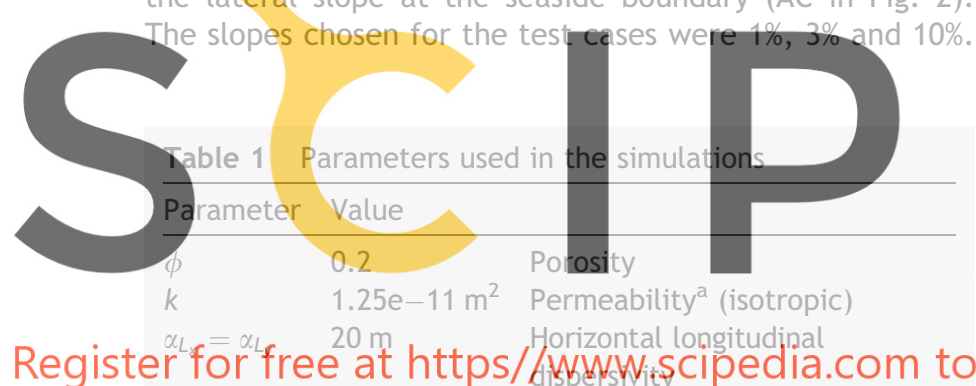
$\alpha_{L_{z}} \quad 2 m$
$D_{\mathrm{m}} \quad 1.0 \mathrm{e}-9 \mathrm{~m}^{2} / \mathrm{s} \quad$ Molecular diffusion coefficient
$\mu \quad 0.001 \mathrm{~kg} / \mathrm{m} \mathrm{s}$ Freshwater viscosity
$q_{\mathrm{b}} \quad 1.5 \mathrm{e}-7 \mathrm{~m} / \mathrm{s} \quad$ Incoming freshwater flux
a This permeability is equivalent to a freshwater hydraulic conductivity of $1.225 \mathrm{e}-4 \mathrm{~m} / \mathrm{s}$.

Table 2 Description of simulations considered in the analysis ( $m_{x}$ and $m_{y}$ are the components of the slope perpendicular and parallel to the sea coast, respectively)

\begin{tabular}{llll}
\hline Test case & $m_{x}$ & $m_{y}$ & $N_{\text {by }}$ \\
\hline 1: Horizontal & 0 & 0 & 0 \\
2: Seawards sloping & 0.01 & 0 & 0 \\
2: Seawards sloping & 0.03 & 0 & 0 \\
2: Seawards sloping & 0.1 & 0 & 0 \\
3: V-shaped & 0 & 0.01 & 0.2 \\
3: V-shaped & 0 & 0.03 & 0.6 \\
3: V-shaped & 0 & 0.1 & 2.04 \\
4: Warped & 0.01 & 0.01 & 0.2 \\
4: Warped & 0.03 & 0.03 & 0.6 \\
4: Warped & 0.1 & 0.1 & 2.04 \\
\hline
\end{tabular}

Assuming the characteristic flux equal to the seawards regional flow that enters the aquifer through the inland boundary $q_{\mathrm{b}}$, these slopes result in $N_{\text {by }}$ values of $0,0.2$, 0.6 and 2.04 . Slopes of $0.5-1.5 \%$ are common in coastal aquifers. An example is the main aquifer of the Llobregat delta (Barcelona, Spain) (Simó et al., 2005) with slopes up to $1 \%$. Larger slopes can be found in complex aquifer settings such as Campo de Dalias (Almería, Spain) (Molina et al., 2002) or Costa de Hermosillo (Sonora, Mexico) (Rangel-Medina et al., 2003) or associated to the filling of submarine canyons.

Computer simulations were performed with SUTRA (Voss and Provost, 2002). The iterative methods chosen to solve the linear system of equations were the conjugate gradient method for the flow equation and GMRES for the transport equation. The mesh consisted of $36 \times 73 \times 11$ nodes and 25,200 hexahedral elements. This mesh was a result of a previous sensitivity analysis. We chose the smallest grid that guaranteed the stability of the solution. Elements were refined in the areas potentially occupied by seawater intrusion, whereas elements located far away from the coast were coarser. As a result, horizontal discretization was finer near the seaside boundary and along the boundary representing the symmetry axis ( $A B$ in Fig. 2 ) with a resolution of $25 \mathrm{~m} \times 25 \mathrm{~m}$. Furthermore, a fine discretization in the vertical direction was carried out to achieve a good resolution of the interface shape and to avoid numerical disper-

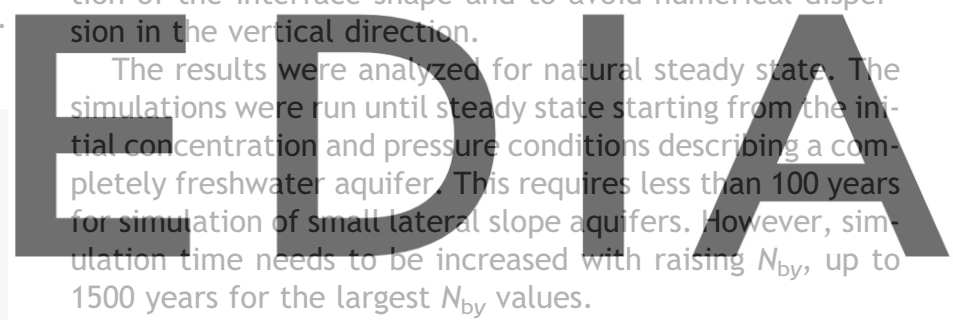

\section{download the version without the watermark} Results

In order to compare the result of the simulations, the seawater-freshwater interface is defined as the isosurface of $50 \%$ seawater concentration. The "toe" penetration is defined as the distance (measured along the $x$ axis direction) between the seaside boundary and the freshwater-seawater interface at the aquifer bottom. The results are presented as a function of the slope $\left(m_{x}\right.$ or $\left.m_{y}\right)$ and are compared with the horizontal aquifer results that are taken as a reference.

\section{Aquifers without a lateral slope}

The interface positions for the horizontal (case 1) and seawards sloping (case 2 ) aquifers with 1\%, 3\% and 10\% slopes are shown in Fig. 4a. When the slope is directed towards the sea Fig. 4a, intrusion patterns resemble those of horizontal aquifers. In other words, the interface geometry is not significantly affected by this slope. As the slope increases, the interface is slightly displaced seawards. The toe is somewhat displaced seawards because of the no flow (nor transport) bottom boundary condition and although the interface shape is the same, as the slope increases, the intersection of the interface with the aquifer bottom occurs closer to the seaside boundary. 
(a) Cases with $\mathrm{N}_{\text {by }}=0$

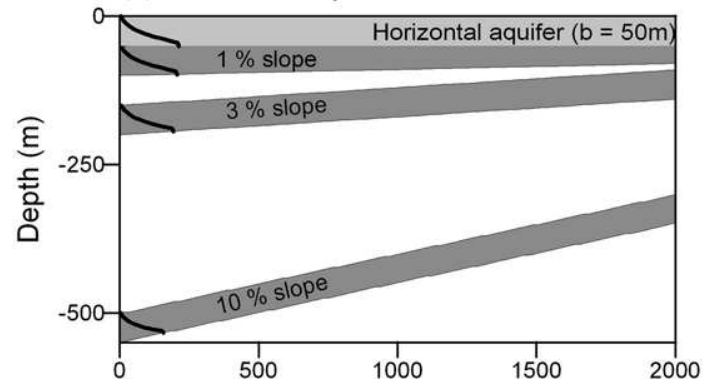

(b) Warped aquifers $(\mathrm{Nby}>0)$

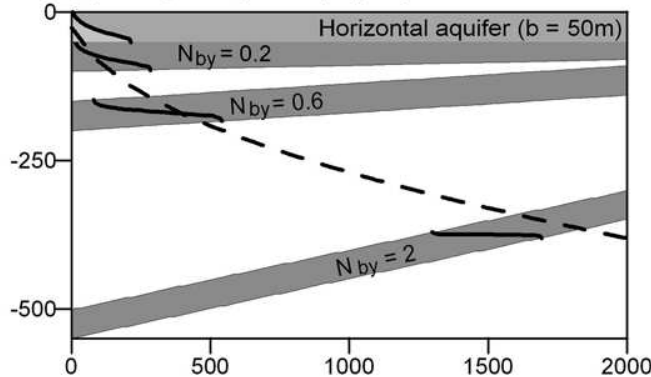

(c) V-shaped aquifers $\left(\mathrm{N}_{\text {by }}>0\right)$

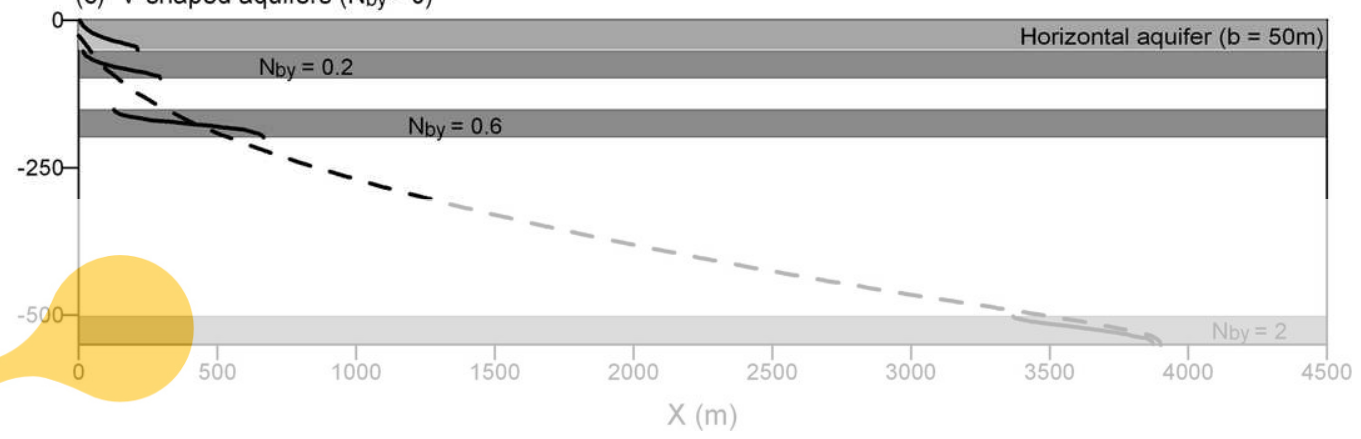

Figure 4 Interface position in the central cross-section (BA in Fig. 2) of horizontal, seawards sloping (a), warped (b) and V-shaped aquifers (c). The dashed line represents the interface for a horizontal aquifer of large thickness with the same inland unit flux.

axizontal axis is distance to the

Lateral sloping aquifers

The saltwater intrusion pattern discussed above is strongly modified in aquifers with lateral slope $\left(N_{b y}>0\right)$. This is illustrated in Fig. 4b and c, which displays the interface location at the central cross-section (AB in Fig. 2 ) in aquifers with lat-

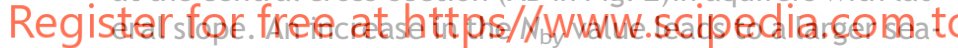
water penetration in this central section. It should be noted that the interface for these aquifers roughly coincides with that of an horizontal aquifer of large thickness with the same unit flux and dispersivity (dashed line in Fig. 4b and $c$ ). This result suggests that the equilibrium between

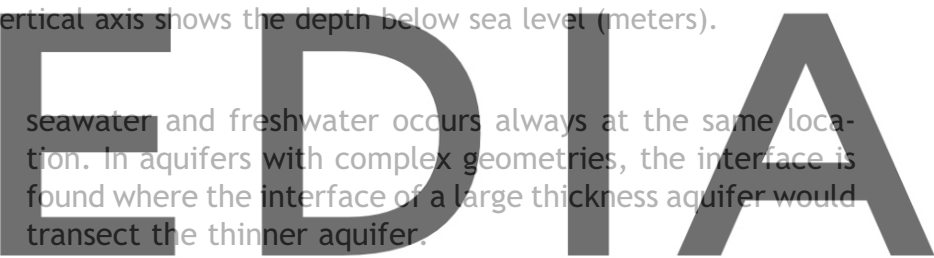

Enhanced seawater intrusion in the deepest part can be illustrated by comparing the velocity vectors in a seawards

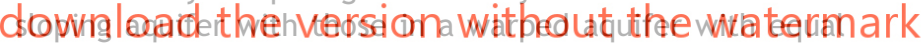
$m_{x}(10 \%)$. Velocity fields and interfaces in the central cross-section of the aquifer are shown in Fig. 5. Vectors show the expected local flow directions in the sloping aquifer (Fig. 5a). Freshwater discharges to the sea, and a vertical convective cell is formed by saltwater entering from the a

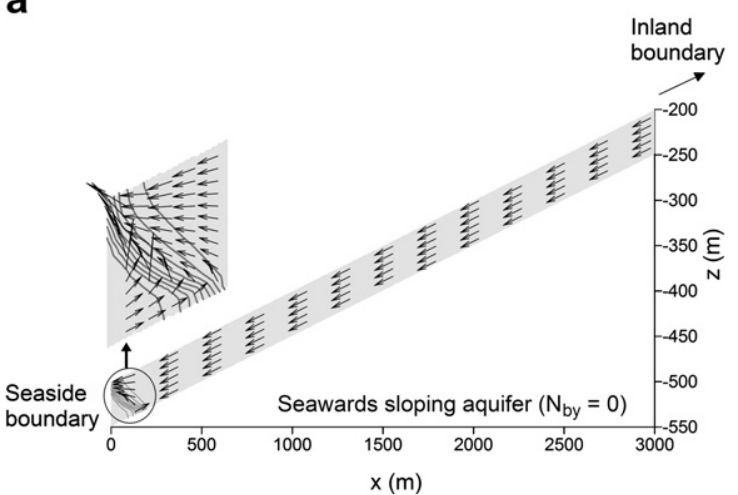

b

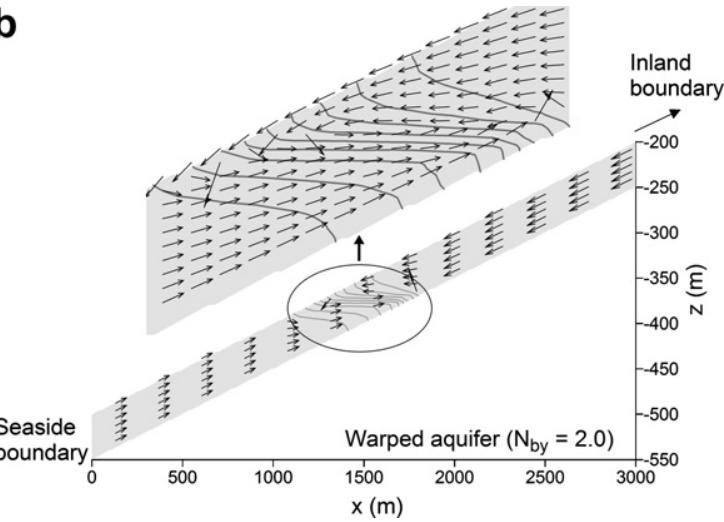

Figure 5 Velocity vectors on the aquifer central cross-section (AB vertical section in Fig. 2) projected in the $X Z$ plane: (a) Crosssection of a seawards sloping aquifer with a $10 \%$ slope. Note the typical vertical convection cell, with seawater entering the lowest part of the aquifer and exiting in the upper part. (b) Cross-section of a warped aquifer with $N_{\text {by }}=2.0$. Note that in this section, seawater enters the whole aquifer thickness. Vector lengths indicate the magnitude of the velocity in each element. 
seaside. However, the interface is at some distance from the sea boundary in the warped aquifer (Fig. 5b) and there is no discharge of freshwater. The velocity vectors suggest that seawater flows inland and mixes with the incoming freshwater along the interface area. Surprisingly, there is neither seawater nor freshwater discharge to the sea in this section. This apparently unrealistic result makes sense when the problem is analyzed in three dimensions. The velocity field at the aquifer bottom of lateral sloping aquifers shows that the flow field is mainly horizontal (Fig. 6). Seawater enters the aquifer at the deepest zone and the lateral slope causes the convection cell in the saltwater wedge to develop sideways. This flow field results in a farthest seawater penetration in the deepest section of the aquifer. This also explains why seawater velocities are reduced near the interface in Fig. 5. Seawater is actually deflected sideways and upslope. Freshwater is pushed by the incoming seawater and can only discharge in the shallower parts of the shore. The net effect is a sub-horizontal convection cell caused by lateral recirculation of seawater.
Both saltwater penetration and interface shape are conditioned by the 3D pattern of the flow field. Therefore, seawater penetration is different in the central and in the lateral cross-sections in all cases with $N_{\text {by }}>0$. The relationship between seawater penetration (toe position) in a central cross-section and $N_{\text {by }}$ is represented in Fig. 7a for all simulated cases. Toe penetration increases significantly with the lateral slope in the aquifer central section. A large divergence between the results is observed when $N_{\text {by }}=2$. This divergence, which is not remarkable for smaller $N_{\text {by }}$ values, can be explained by comparing Fig. $5 b$ and $c$. The different aquifer depth at the central section controls the actual location of the interface. In the shallowest section (section CD in Fig. 2) the opposite effect is observed (Fig. 7b). The interface penetration decreases in this section as the $N_{\text {by }}$ number increases due to the larger amount of freshwater that is diverted to the shallowest parts of the aquifer.

The increase of inland seawater penetration with $\mathrm{N}_{\text {by }}$ explains why numerical simulations take so long to reach the
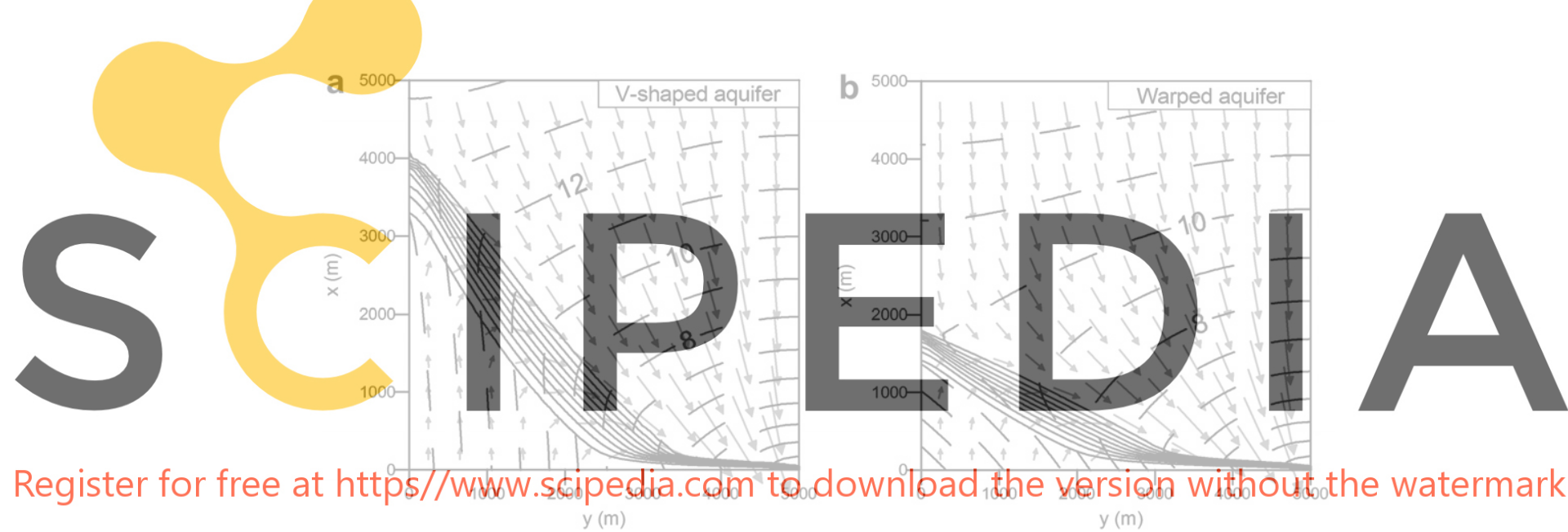

Figure 6 Velocity vectors at the aquifer bottom projected in the XY plane, isoconcentration lines and equivalent freshwater head isolines (dashed lines) in a V-shaped (a) and warped (b) aquifer with $N_{\text {by }}=2.0$. Note that water entering the aquifer through its lowest point tends to exit at the much higher right hand corner, thus leading to an essentially horizontal convention cell. The lines (10-90\% mixing lines) show the position and width of the mixing zone at the aquifer bottom. Note that both fresh and salt waters are deflected sideways towards the high end of the outflowing boundary.

(a) Deep cross section

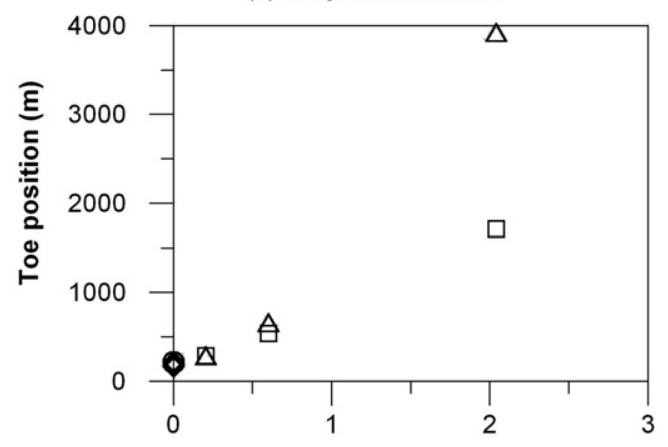

(b) Shallow cross section

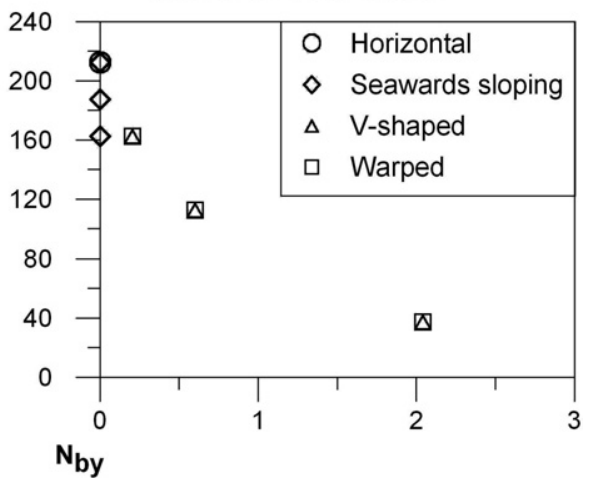

Figure 7 Toe position for the central cross-section (a) and the lateral cross-section (b). Note the relation between the $N_{\text {by }}$ number and the increase in salt penetration in the central section. This effect is also accompanied by a decrease in toe penetration at the lateral boundary caused by the convergence of freshwater outflow in the upslope part of the aquifer. 
steady state. Response time increases with the square of distance for diffusion problems. It must be stressed, however, that the sub-horizontal cell develops from the beginning of the simulation. Thereby, while these kinds of convection cells may take a long time to reach steady state, they are expected to develop as soon as natural flow conditions are established.

The three-dimensionality of the flow field causes that the saltwater income is not equally distributed along the coast line (Fig. 8). Vertically integrated salt flux is virtually equal to 0 for aquifers without a lateral slope as expected because of the symmetry of the flow field. However, in lateral sloping aquifers (warped and V-shaped) an inflow and an outflow dominated zone can be distinguished. Salt enters the aquifer through the deepest part of the seaside boundary and discharge takes place upslope. The maximum discharge location depends on the extent of the lateral cell, and therefore, on the $N_{\text {by }}$ number. Fig. 6 shows that the lateral cell affects about $3000 \mathrm{~m}$ of the coast line for $N_{\text {by }}$ equal to 2 . Therefore, in these cases, the maximum discharge points are located about $3000 \mathrm{~m}$ away from the central and deepest section of the aquifer. These values become 500 and $900 \mathrm{~m}$ for $N_{\text {by }}$ equal to 0.2 and 0.6., respectively. This heterogeneous distribution of the seawater flow can be of extreme importance to understand groundwater discharge patterns in coastal aquifers.

The three dimensionality of the flow field also implies that the generally used estimation of the saltwater wedge toe position via the Ghyben-Herzberg approximation is not valid when the aquifer has a lateral slope. A constant horizontal freshwater flow perpendicular to the coast cannot be assumed. In Appendix A, an approximation is derived for the case of laterally sloping aquifers based on the Ghyben-Herzberg assumptions (sharp interface and immobile saltwater). Fig. 9 compares the model results (toe location) and the toe position calculated with the tilted Ghyben-
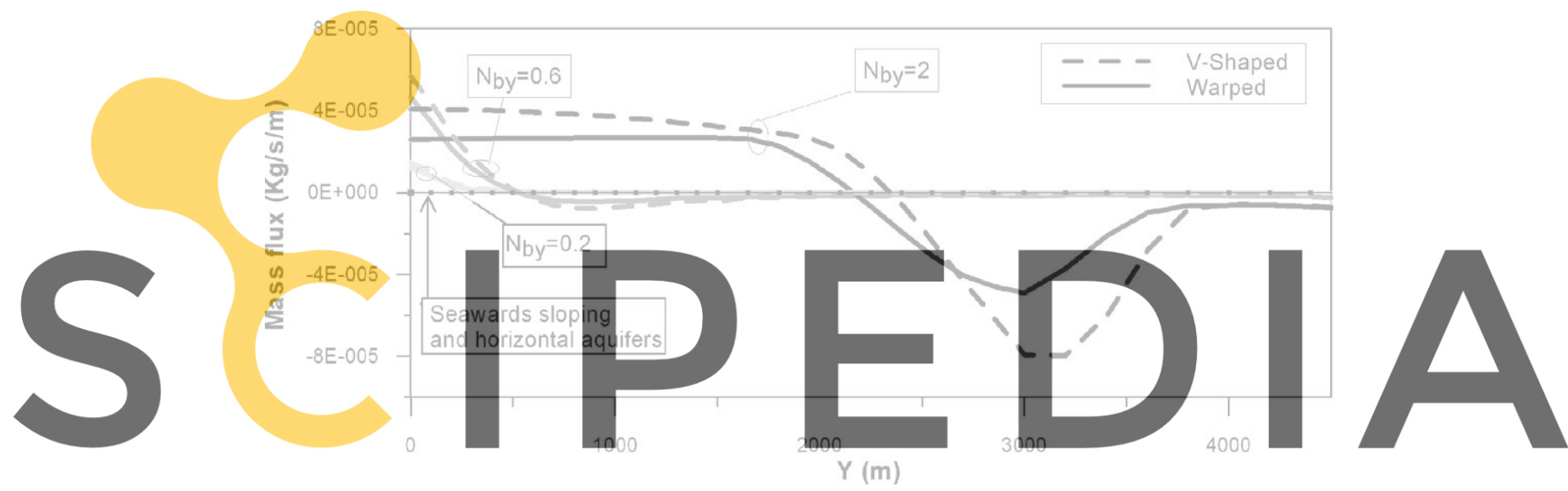

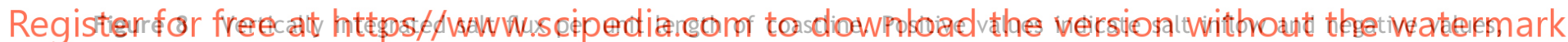
outflow. The minimum salt flux in each case indicates the location of the main salt discharge point. Note that the mass flux is 0 along the whole boundary in both horizontal and seawards sloping aquifers. However, seawater enters the deepest parts of the aquifer and exits at through the shallower parts, though not the shallowest, in aquifers with a lateral slope.
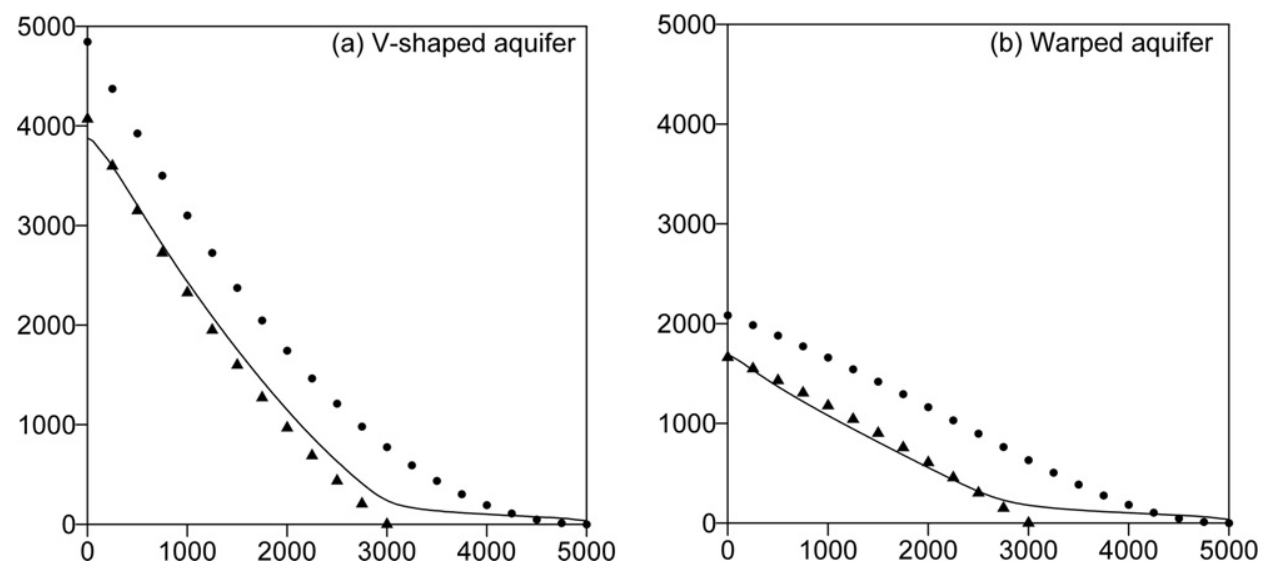

Figure 9 Model results (toe location is shown as a line) at the bottom of the V-shaped (a) and warped (b) aquifers with $N_{b y}=2.0$. Also shown is the locations of the interface derived from the Ghyben-Herzberg approximation of Appendix A for two dimensional areal aquifers with the same elevation. Circles depict the tilted interface position on the assumption that it intersects the coastline at the shallowest point. Triangles represent the solution assuming that the interface intersects the boundary at $y=3000 \mathrm{~m}$, the main saltwater discharge point as shown in Fig. 8. 
Herzberg approximation (Appendix A). Two different interface positions were calculated. The first position assumes that the interface intersects the coast line at the shallowest point, which is the standard in 2D vertical models and which overestimates seawater penetration. The second position is based on the assumption on that the interface intersects the coast line at the main saltwater discharge point (Fig. 8). The second approximation fits the model results more accurately but presents the disadvantage that the main discharge point is not known in advance. Toe penetration is slightly overestimated by the first approximation. Nevertheless, this can be considered as a good approximation to the solution of the interface position as in vertical crosssections.

\section{Sensitivity analysis}

Other parameters may affect the behavior of seawater intrusion in aquifers with variable depths. In order to deter- mine whether this effect was well characterized by the $N_{\text {by }}$ number, the sensitivity of toe position to dispersivity coefficients, freshwater boundary inflow $\left(q_{\mathrm{b}}\right)$ and aquifer thickness (b) was studied. Anisotropy in the hydraulic conductivity has not explicitly been studied. However, the results for the aquifer thickness can be extrapolated to the anisotropy effect because, except for the molecular diffusion, changes in the anisotropy ratio are strictly equivalent to changes in aquifer thickness.

\section{Dispersivity}

The results of the sensitivity analysis with respect to dispersivity are shown in Fig. 10. The toe penetration in a central cross-section shows the expected behavior. As dispersivity coefficients are increased, the toe penetration decreases. Toe penetration is more sensitive to transversal than to the longitudinal dispersivity. However, in both cases, sensitivity is low and does not affect the behavior discussed above.

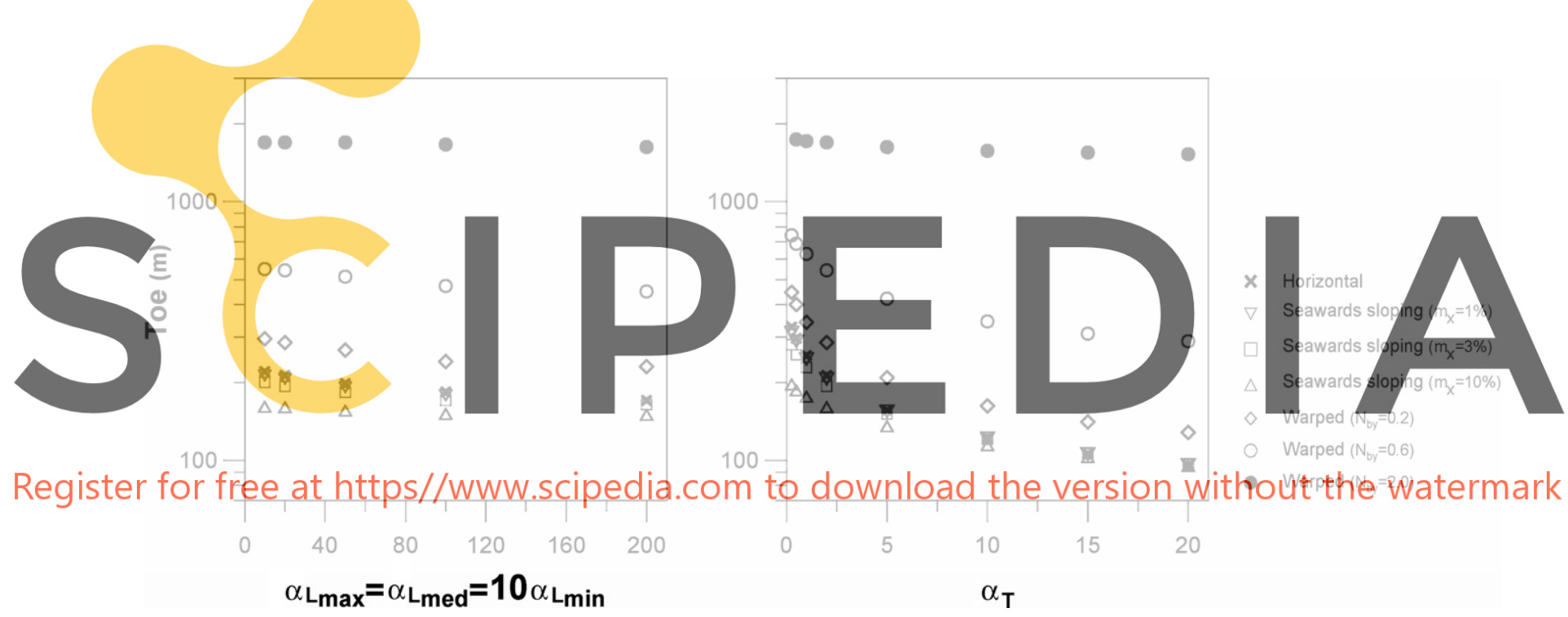

Figure 10 Sensitivity of toe penetration to the longitudinal (left) and transversal (right) dispersivity values in the aquifer central cross-section for different aquifer geometries.

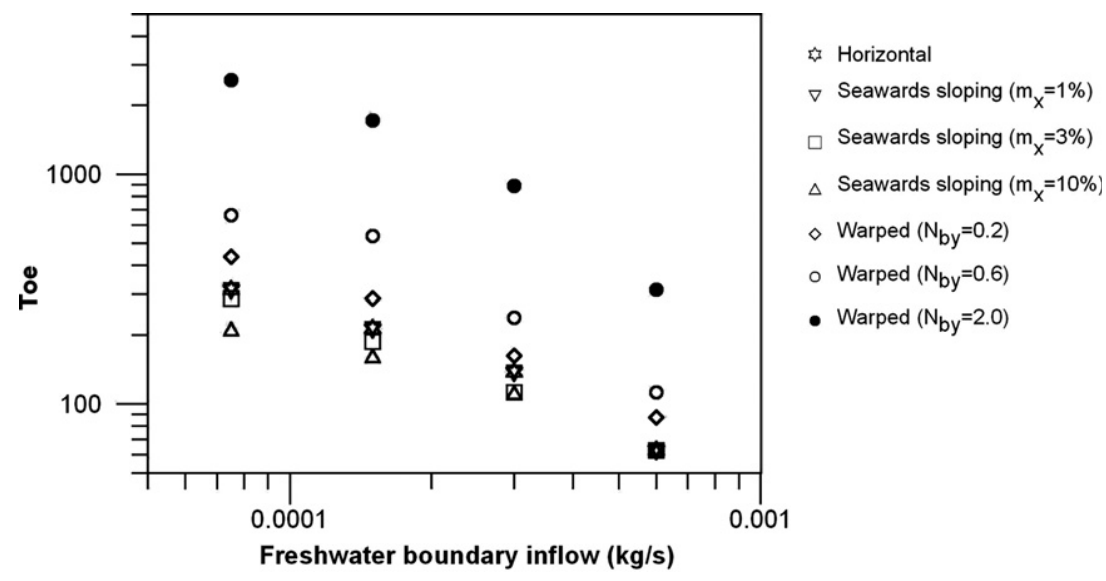

Figure 11 Sensitivity of toe penetration to the freshwater inflow through the inland boundary in the aquifer central cross-section for different aquifer geometries. 


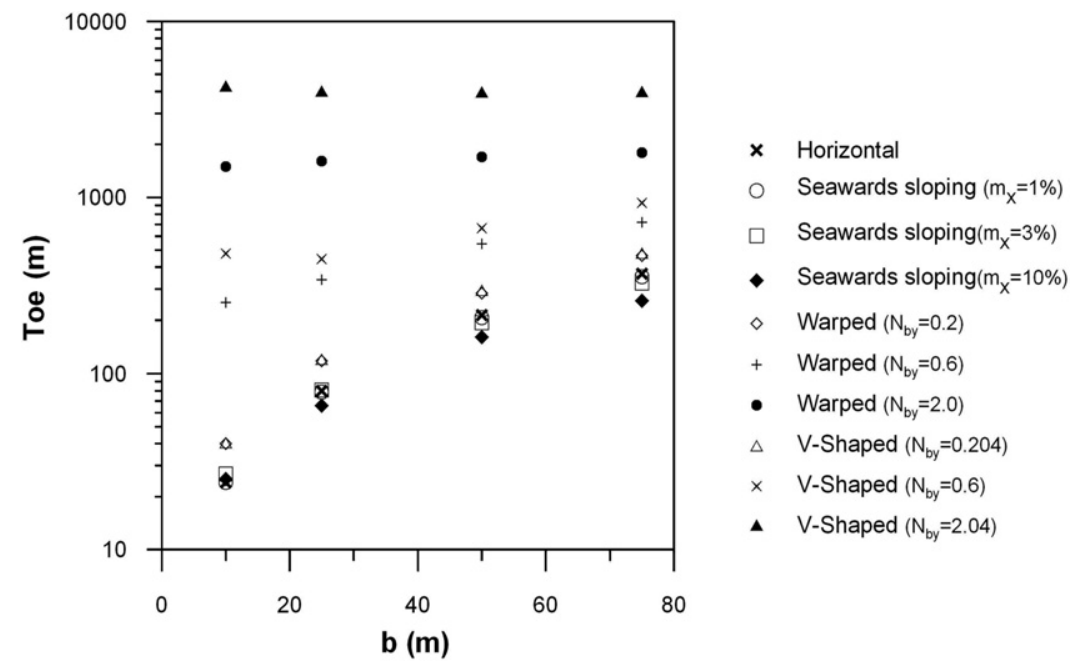

Figure 12 Sensitivity of toe penetration to different thicknesses in the aquifer central cross-section for the different considered aquifer geometries.

Freshwater boundary inflow

Freshwater boundary inflow $\left(q_{\mathrm{b}}\right)$, assumed as the characteristic flux of the problem, appears in the $N_{\text {by }}$ expression. A

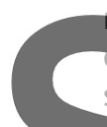

number of simulations were carried

of this factor in the seawater in

sloping aquifers. The toe positions

vatues of the freshwater inflow are

of the geometries considered. T

flow, the smaller the saltwater

different behavior for the aquifers with $N_{\text {by }}>0$ is still ob-

served for higher values of the freshwater boundary inflow.

Registequifer fhigenęs https//www.scipedia.com to

As stated above, saltwater penetration depends on aquifer thickness provided the remaining parameters are kept constant. Moreover, the effect of the geometry of the aquifer boundaries should be smaller with increasing aquifer thickness because of the reduced confinement of the buoyancy term. Therefore, aquifer thickness is one of the parameters with the greatest impact on seawater intrusion behavior. The results for different simulations with different values of the aquifer thickness are presented in Fig. 12. The greater seawater penetration in the deepest aquifer sections for the warped and V-shaped aquifers is still present in all values of aquifer thickness.

\section{Conclusions}

Analysis of seawater intrusion problems is often carried out in vertical cross-sections perpendicular to the sea or areal 2D models using either simplified analytical solutions (based on Ghyben-Herzberg approximation) or sophisticated numerical codes. However, the seawater intrusion patterns in horizontally extensive aquifers are heavily dependent on the shape of their boundaries. Intrusion patterns in aquifers with laterally varying bottom elevation are qualitatively different. The main differences stem from a lateral, essen- tially horizontal, convection cell that develops along the ocean side of the aquifer in aquifers with valley-shaped bottoms. This is due to the slope parallel to the coast in the impermeable aquifer bottom. Lateral convection cells cause the seawater wedge to penetrate farthest inland-in
the deepest part of the aquifer.
These effects can be quantified by means of a lateral
buoyancy dimensionless number, $N_{\text {by }}$. Lateral convection
cells are developed with $N_{\text {by }}$ numbers higher than approxi-
mately 0.4 . Modeling such effects demands a ful/ knowtedge
of the $3 \mathrm{D}$ geometry of the bottom aquifer and this can only be achieved by using 3D density-dependent groundwater flow and transport codes. Nevertheless, reliable approxima-

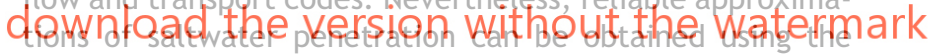
tilted Ghyben-Herzberg approximation of Appendix A.

\section{Acknowledgements}

This work was funded by the European Commission (SALTRANS project, contract EVK1-CT-2000-00062), the Catalonian Water Agency (ACA) and the Spanish Geological Survey (IGME). The first author was supported by the Autonomous Government of Catalonia with a FI doctoral scholarship and by the Technical University of Catalonia (UPC) with a scholarship to complete the Ph.D. thesis.

\section{Appendix A. Tilted Ghyben-Herzberg approximation}

An approximate position of the saltwater wedge in coastal aquifers is normally calculated using the Ghyben-Herzberg approximation in a cross-section perpendicular to the coast. This equation cannot be applied in aquifers with lateral slope. The 3D character of the flow field implies that freshwater flow is not perpendicular to the coast. However, a new approximation for thin laterally sloping aquifers can be used to obtain the tilted interface position. Two cases 


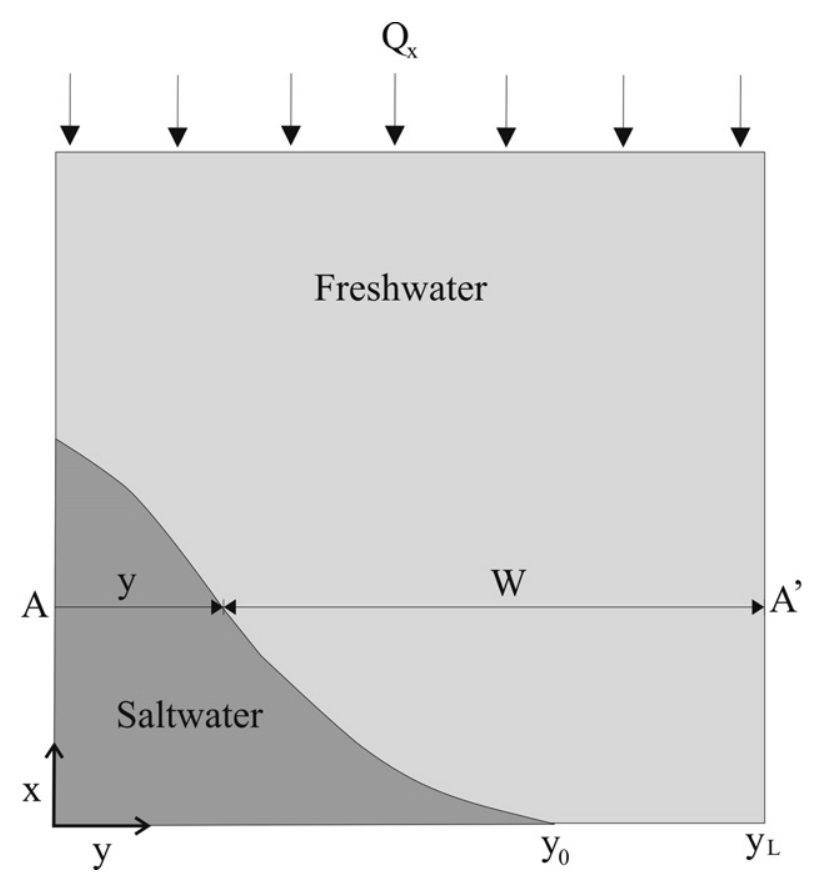

Figure A.1 Plan view of the aquifer domain and some of the variables that appear in the calculations.

are considered here: (1) V-shaped aquifers and (2) warped aquifers. The general domain is shown in Fig. A.1.

Adopting the Dupuit-Forchheimer assumption, flow across the $A-A^{\prime}$ section, is given by Darcy's law

$Q_{x}=T W(x) \frac{\partial h}{\partial x}$

where $Q_{x}$ is the freshwater flowing through the $A-A^{\prime}$ section; $T$ the aquifer transmissivity; $W(x)=\left(y_{L}-y\right)$ the aquifer width in which freshwater flows; $y$ the interface position in $y$ direction.

Ghyben-Herzberg assumptions of immobile saltwater and sharp interface (there is no mixing zone) imply

$h(x, y)=-\epsilon \zeta$,

where $\zeta(x, y)$ is the elevation of the interface.

Expressing $W$ in terms of the equation of the aquifer surface, requiring the interface to satisfy (A.2) and integrating in $x$ yields the equation for the interface as shown below.

\section{A.1. V-shaped aquifers}

In aquifers described as V-shaped and shown as case 3 in Fig. 3, the geometry of the boundary planes have the following expression:

$\zeta-\zeta_{L}=m\left(\mathbf{y}-y_{L}\right)=m W$,

where $m$ is the slope of the plane.

Solving (A.3) for $W$, substituting $\zeta$ by means of (A.2) and integrating along the flow direction $(x)$ leads to

$$
\begin{aligned}
& m \int_{0}^{x} Q_{x} \mathrm{~d} x^{\prime}=T \int_{h_{0}}^{h}\left(\frac{h^{\prime}(x)}{\epsilon}+\zeta_{L}\right) \mathrm{d} h^{\prime}, \\
& m Q_{x} x=T\left[\frac{h^{2}-h_{0}^{2}}{2 \epsilon}+\left(h-h_{0}\right) \zeta_{L}\right],
\end{aligned}
$$

where $h_{0}$ is the freshwater head $\left(\zeta_{0} \epsilon\right)$ at the point where the interface intersects the seaside boundary. $Q_{x}$ is assumed to be constant (i.e., there is no areal recharge). Again using (A.2) for $h$ and (A.3) for $\zeta$ yields the areal equation of the interface

$x=\frac{T m \epsilon}{2 Q}\left[\left(y-y_{L}\right)^{2}-\left(y_{0}-y_{L}\right)^{2}\right]$,

where $y_{0}$ is the $y$ value at the interface intersection with the coast line. A priori, one does not know $y_{0}$ and several approximations should be made:

(1) If the interface intersects the coast line in $y_{L}$, then

$$
x=\frac{T m \epsilon}{2 Q}\left(y-y_{L}\right)^{2} .
$$

(2) If the interface intersects the coast line somewhere between $y=0$ and $y_{L},(A .6)$ must be applied.

\section{A.2. Warped aquifers}

In warped aquifers designated as case 4 in Fig. 3, the geometry of the boundary surfaces has the following expression:

$\zeta-\zeta_{L}=-\frac{m}{L}\left(y_{L}-y\right)\left(x_{L}-x\right)$,

where $m$ is the slope in $x$ and $y$ direction and $L$ the model domain length.

Following the same procedure as above, the final expression for the interface equation for warped aquifers is

$x=x_{L}\left(1-\sqrt{\frac{L Q+T \epsilon m\left(y_{L}-y_{0}\right)^{2}}{L Q+T \epsilon m\left(y_{L}-y\right)^{2}}}\right)$.

As stated above, two different approximations for $y_{0}$ can be adopted. First, we assume that the interface intersects the coast line at $y_{L}$, in which case the interface equation simplifies to

$x=x_{L}\left(1-\sqrt{\frac{L Q}{L Q+T \epsilon m\left(y_{L}-y\right)^{2}}}\right)$.

Second, we assume that the interface intersects the coast line somewhere between $y=0$ and $y_{L}$, in which case (A.9) must be used.

\section{References}

Ackerer, P., Younès, A., Mosé, R., 1999. Modeling variable density flow and solute transport in porous medium: I. Numerical model and verification. Transport Porous Med. 35, 345-373.

Assouline, S., Shavit, U., 2004. Effects of managemen policies, including artificial recharge, on salinization in a sloping aquifer: The Israeli Coastal Aquifer case. Water Resour. Res. 40, W04101, doi:10.1029/2003WR002290.

Bachu, S., 1995. Flow of variable density formation water in deep sloping aquifers: review of methods of representation with case studies. J. Hydrol. 164, 19-38.

Bachu, S., Karsten, M., 2002. Flow of variable-density formation water in deep sloping aquifers: minimizing the error in representation and analysis when using hydraulic-head distributions. J. Hydrol. 259, 49-65. 
Bear, J., 1972. Dynamics of Fluids in Porous Media. Elsevier, Amsterdam.

Benkabbour, B., Toto, E., Fakir, Y., 2004. Using DC resistivity method to characterize the geometry and the salinity of the Plioquaternary consolidated coastal aquifer of the Mamora plain, Morocco. Environ. Geol. 45, 518-526. doi:10.1007/s00254-003-0906-y.

Cooper, H.H.-Jr., 1964. A hypothesis concerning the dynamic balance of fresh water and salt water in a coastal aquifer. Water-Supply Paper 1613-C, US Geological Survey.

Diersch, H.-J.G., Kolditz, O., 1998. Coupled groundwater flow and transport: 2. Thermohaline and 3D convection systems. Adv. Water Resour. 21 (5), 401-425.

Diersch, H.-J.G., Kolditz, O., 2002. Variable-density flow and transport in porous media: approaches and challenges. Adv. Water Resour. 25 (8-12), 899-944.

Dorgarten, H.-W., Tsang, C.-F., 1991. Modelling the density-driven flow movement of liquid wastes in deep sloping aquifers. Ground Water 29 (5), 655-662.

Fein, E., Schneider, A., 1999. Ein Programmpaket zur Modellierung von Dichteströmungen. Tech. Rep. 139, Gesellschaft für Anlagen - und Reaktorsicherheit (GRS) mbH, Braunschweig, Germany.

Flores-Márquez, E., Campos-Enríquez, J., Chávez-Segura, R., Castro-García, J., 1998. Saltwater intrusion of the Costa de Hermosillo aquifer, Sonora, Mexico: a numerical simulation. Geofísica Internacional 37 (3), 131-151.

Gambolati, G., Putti, M., Paniconi, C., 1999. Three-dimensional model of coupled density-dependent flow and miscible salt transport in groundwater. In: Bear, J., Cheng, A.H.-D., et al. (Eds.), Seawater Intrusion in Coastal Aquifers - Concepts, Methods and Practices. Kluwer Academic Publishers, Dordrecht, Netherlands, pp. 315-362 (Chapter 10).

Ghyben, B.W., 1889. Nota in verband met de voorgenomen put boring nabij Amsterdam. The Hague. K. Inst. Ing. Tydschrift, pp. 8-22.

Gingerich, S., Voss, C., 2002. Three-dimensional variable-density flow simulation of a coastal aquifer in southern Oahu, Hawaii, USA. In: Boekelman, R.e.a. (Ed.), Proceedings SWIM17 Delft. Delft University of Technology, Delft, pp. 93-103.

Guo, W., Langevin, C., 2002. SEAWAT - User's guide to SEAWAT: a computer program for simulation of three-dimensional varibledensity ground-water flow. No. 6 in Techniques of Water Resources Investigations. USGS, Tallahassee, FL, p. 77 (Chapter A).

Herzberg, A., 1901. Die Wasserversorgung einiger Nordseebäder. J. Gasbeleuchtung Wasserversorgung 44, 815-819, 842-844.

Huyakorn, P., Andersen, P.F., Mercer, J., White, H., 1987. Saltwater intrusion in aquifers: development and testing of a three-dimensional finite element model. Water Resour. Res. 2 (23), 293-312.

Johannsen, K., Kinzelbach, W., Oswald, S., Wittum, G., 2002. The saltpool benchmark problem - numerical simulation of saltwater upconing in a porous medium. Adv. Water Resour. 25 (3), $335-348$.

Kipp, K.J., 1986. HST3D. A computer code for simulation of heat and solute transport in three-dimensional groundwater flow systems. Water-Resources Investigations 86-4095, IGWMC, International Ground Water Modelling Center. USGS.

Kolditz, O., Habbar, A., Kaiser, R., Schulze-Ruhfus, M., Thorenz, C., 1998. ROCKFLOW - Theory and Users Manual. Release 3.2.
Institut für Strömungsmechanik und Elektronisches Rechnen im Bauwesen, Universität Hannover.

Lahm, T., Bair, E., VanderKwaak, J., 1998. The role of salinityderived variable-density fluid flow in the displacement of brine from shallow, regionally extensive aquifers. Water Resour. Res. 34 (6), 1469-1480.

Malkovsky, V., Pek, A., Tsang, C., 2002. Dynamic stabilization of heat-generating liquid waste plume in a sloping aquifer. J. Hydrol. 258, 69-82.

Milnes, E., Renard, P., 2004. The problem of salt recycling and seawater intrusion in coastal irrigated plains: an example from the Kiti aquifer (Southern Cyprus). J. Hydrol. 288 (3-4), 327343.

Molina, L., Vallejos, A., Pulido-Bosch, A., Sanchez-Martos, F., 2002. Water temperature and conductivity variability as indicators of groundwater behaviour in complex aquifer systems in the SouthEast of Spain. Hydrological Processes 16 (17), 3365-3378.

Oswald, S., Kinzelbach, W., 2004. Three-dimensional physical benchmark experiments to test variable-density flow models. J. Hydrol. 290 (1-2), 22-42.

Oude Essink, G., 1998. Simulating density dependent groundwater flow: the adapted MOC3D. In: Proc. 15th Salt Water Intrusion Meeting, Ghent, Belgium, pp. 69-79.

Oude Essink, G., 2001. Salt water intrusion in a three-dimensional groundwater system in The Netherlands: a numerical study. Transport Porous Med. 43 (1), 137-158.

Paniconi, C., Khlaifi, I., Lecca, G., Giacomelli, A., Tarhouni, J., 2001. A modelling study of seawater intrusion in the Korba coastal plain, Tunisia. Phys. Chem. Earth (B) 26 (4), 345-351.

Rangel-Medina, M., Monreal-Saavedra, R., Morales-Montaño, M., Castillo-Gurrola, J., 2003. Caracterización geoquímica e isotópica del agua subterránea y determinación de la migración de la intrusión marina en el acuífero de la Costa de Hermosillo, Sonora, Mexico. In: Tecnología de la intrusión de agua de mar en acuíferos costeros: Países mediterráneos. IGME, Madrid.

Sauter, F., Leijnse, A., Beusen, A., 1993. METROPOL. User's Guide. Tech. Rep. 725205.003, National Institute of Public Health and Environmental Protection, Bilthoven, the Netherlands.

Sciabica, M.G., Paniconi, C., Barrocu, G., 1994. Three-dimensional model of saltwater intrusion in the Capoterra coastal aquifer system (Sardinia). In: Barrocu, G. (Ed.), Proceedings of the 13th Salt-Water Intrusion Meeting. Dipartimento di Ingegneria del Territorio, Università di Cagliari, Cagliari, Italy, pp. 77-86.

Simó, J., Gàmez, D., Salvany, J., Vàzquez-Suñé, E., Carrera, J., Barnolas, A., Alcalà, F., 2005. Arquitectura de facies de los deltas cuaternarios del río Llobregat, Barcelona, España. Geogaceta 37.

Strack, O., 1995. A Dupuit-Forcheimer model for three-dimensional flow with variable density. Water Resour. Res. 31 (12), 3007-3017.

Voss, C.I., Provost, A., 2002. SUTRA, A model for saturatedunsaturated variable-density ground-water flow with solute or energy transport. Water-Resources Investigations Report 024231, US Geological Survey.

Ward, D., 1991. Data input for SWIFT/386, version 2.50. Technical Report, Geotrans, Sterling, VA.

Xue, Y., Xie, C., Wu, J., Lie, P., Wang, J., Jiang, Q., 1995. A 3dimensional miscible transport model for seawater intrusion in China. Water Resour. Res. 31 (4), 903-912. 